\title{
O sujeito nos textos de Vigotski e do Círculo de Bakhtin: implicações para a prática da pesquisa em educação ${ }^{\star}$
}

\author{
Maria Teresa de Assunção Freitas, ${ }^{I, \star}$ Alessandra Sexto Bernardes, ${ }^{I}$ \\ Ana Paula Marques Sampaio Pereira, ${ }^{I}$ Maria Leopoldina Pereira ${ }^{I I}$ \\ ${ }^{I}$ Universidade Federal de Juiz de Fora, Juiz de Fora, MG, Brasil \\ ${ }^{I I}$ Universidade Federal do Rio de Janeiro, Rio de Janeiro, RJ, Brasil
}

\begin{abstract}
Resumo
Neste artigo a concepção de sujeito nas obras de Vigotski e Bakhtin e seu Círculo é revisitada em um diálogo com as produções do Grupo de Pesquisa LIC - Linguagem, Interação e Conhecimento da Faculdade de Educação da Universidade Federal de Juiz de Fora, em seus 19 anos de trajetória no campo da pesquisa em educação. Considerando o outro como peça indispensável de todo o processo dialógico que permeia as teorias de Vigotski e Bakhtin, delineia-se brevemente o cerne do fazer metodológico do grupo de pesquisa LIC que, ancorado no materialismo histórico e dialético, compreende o(s) sujeito(s) da pesquisa como participantes responsivos, ativos, dialógicos. Sem a pretensão de formatar uma concepção de sujeito segundo os teóricos russos, são enfocadas as condições de possibilidades que permitem pensar a produção de sentidos nos aspectos interconstitutivos de suas múltiplas dimensões: singular e coletiva, subjetiva e objetiva, biológica e cultural, histórica e dialética.
\end{abstract}

Palavras-chave: concepção de sujeito; pesquisa em educação; Vigotski; Bakhtin.

\section{The subject in the works of Vigotski and of the Circle of Bakhtin: implications for the practice of research in education}

\begin{abstract}
In this article the concept of subject in the works of Vigotski and Bakhtin and their circles is revisited in a dialogue with the LIC ("Linguagem, Interação e Conhecimento" - Language, Interaction and Knowledge) Research Group Production Team, with its 19 years of experience in the Universidade Federal de Juiz de Fora. Considering the other self as an essential part of the whole dialogic process that permeates Vigotski and Bakhtin theoretical frame, the core of methodolical work of the LIC group is outlined. Anchored in the historical and dialectical materialisms, the research subject(s) are understood as responsive, dialogic and active participants. With no pretentions to format a concept of subject according to the russian theorists, the conditions for the possibilities that the role assigned for both to language allows thinking the production of meanings in their multiple dimensions interconstitutive aspects are focused: single and collective, subjective and objective, biological and cultural, historical and dialectical.
\end{abstract}

Keywords: concept of subject; research in education; Vigotski; Bakhtin.

A unicidade única ou singularidade não pode ser pensada;

ela só pode ser

participativamente

experimentada ou vivida.

Mikhail Bakhtin

\section{Introdução}

Neste artigo, revisitamos as obras de Vigotski e de Bakhtin e seu Círculo, dialogando com eles e com nossos interesses de pesquisa, para apresentar a concepção de sujeito que norteia o Grupo de Pesquisa Linguagem, Interação e Conhecimento (LIC) da Faculdade de Educação da Universidade Federal de Juiz de Fora (UFJF), coordenado pela professora Maria Teresa de Assunção Freitas.

Em um percurso de 19 anos de trabalho, desenvolvemos sete pesquisas financiadas pelo CNPq e FAPEMIG tendo como objetos de estudo a leitura-escrita, o letramento digital, computador-internet, cinema, aprendizagem e formação de professores. Nessa trajetória, tendo

\footnotetext{
^ Grupo de Pesquisa Linguagem, Interação e Conhecimento (LIC), coordenado por Maria Teresa de Assunção Freitas na Faculdade de Educação da Universidade Federal de Juiz de Fora (UFJF).

$\star \star$ Endereço para correspondência: Universidade Federal de Juiz de Fora, Faculdade de Educação. Campus Universitario - Martelos. CEP: 36036330 - Juiz de Fora, MG - Brasil. E-mail: freitas.mteresa@gmail.com, asextobernardes@hotmail. com, anapmsp@gmail.com, professsora.dina@ig.com.br.
}

a perspectiva histórico-cultural como referencial teórico, desenvolvemos um fazer metodológico que nos levou a uma compreensão ativa da educação e de seus sujeitos.

\section{O sujeito em Vigotski}

Não há em Vigotski um trabalho específico sobre o sujeito mas revisitando suas obras encontramos diversas pistas que nos levam, a partir de seus construtos teóricos, a desenvolver a concepção de sujeito que fundamenta nossas pesquisas.

No livro A Formação Social da Mente, Vigotski (1999) indica que o indivíduo se constitui a partir de sua interação social com os demais seres da espécie. Signos e palavras são mediadores nessa tarefa e favorecem ao homem a internalização de suas ações externas:

A maior mudança na capacidade das crianças para usar a linguagem como um instrumento para a solução de problemas acontece um pouco mais tarde no seu desenvolvimento, no momento em que a fala socializada do autor (que foi previamente utilizada para dirigir-se a um adulto) é internalizada. Ao invés de apelar para o adulto, as crianças passam a apelar a si mesmas; a linguagem passa, assim, a adquirir uma função intrapessoal além de seu uso interpessoal (VIGOTSKI, 1999, p. 37, grifo do autor). 
A internalização, para Vigotski, consiste na reconstrução interna de uma ação externa ao homem. Ou seja, no desenvolvimento humano, as funções aparecem duas vezes. Primeiro, no nível interpsicológico (entre pessoas), e depois, no intrapsicológico (no interior do indivíduo). "Nesse sentido, a internalização das formas culturais de comportamento envolve a reconstrução da atividade psicológica tendo por base as operações com signos" (VIGOTSKI, 1999, p.75).

Partindo da concepção da linguagem como fundamental na constituição do sujeito, encontramos na obra $A$ construção do pensamento e da linguagem (VIGOTSKI, 2001) uma retomada das teses do materialismo histórico-dialético e a definição do pensamento e da linguagem como linhas que se cruzam no desenvolvimento humano, transformando o pensamento verbal em uma das maiores construções histórico-culturais do sujeito.

Pino (2005) esclarece que Vigotski modificou o modo de pensar da ciência psicológica da época e, consequentemente, o modo de pensar o humano e sua constituição enquanto ser.

A corrente histórico-cultural de psicologia, cuja figura de proa é Lev S. Vigotski constitui uma exceção na história do pensamento psicológico, não só porque introduz a cultura no coração da análise, mas sobretudo porque faz dela a "matériaprima" do desenvolvimento humano que, em razão disso, é denominado "desenvolvimento cultural", o qual é concebido como um processo de transformação de um ser biológico num ser cultural (PINO, 2005, p. 52, grifo do autor).

Desse modo, a partir de Vigotski, podemos compreender o ser enquanto um ser social, cuja humanização depende do subjetivo em contato com o coletivo, isto é, da articulação entre seu caráter biológico, comum à espécie e a cada indivíduo, com o que a cultura lhe oferece e possibilita.

Mediante a essa concepção do duplo nascimento (o nascimento natural e o cultural) descrito por Vigotski, podemos pensar a questão da subjetividade para além de uma concepção pautada na individualização do ser humano:

Podem-se distinguir, dentro de um processo geral de desenvolvimento, duas linhas qualitativamente diferentes de desenvolvimento, diferindo quanto à sua origem: de um lado, os processos elementares, que são de origem biológica; de outro, as funções psicológicas superiores, de origem sócio-cultural. A história do comportamento da criança nasce do entrelaçamento dessas duas linhas (VIGOTSKI, 1999, p. 6, grifo do autor).

O ser humano, nesse sentido, é um ser social, que depende do outro para se tornar ele mesmo. Desde o nascimento, somente quando os primeiros atos da criança adquirem significação para o outro, é que eles se tornam significativos para ela, como demonstrado por Vigotski (1999, p.74-75) através do ato de apontar. Ao tentar agarrar um objeto, a ação da criança é interpretada pela mãe como o ato de apontar, e ela recebe o objeto como resposta. Dessa forma, é através da interferência da mãe que a criança passa a significar o seu gesto.

Fractal, Rev. Psicol., v. 27 - n. 1, p. 50-55, 2015
Considerar o homem como ser social vai além da concepção de existir na sociedade. O simples fato de nascer pertencente a uma cultura ou tempo/espaços próprios não faz do ser algo além de seu caráter biológico. Somente e a partir da interação com o outro, da significação dos atos humanos para si, da compreensão de seu papel na sociedade, é que o ser se torna cultural, se "humaniza”. Segundo Vigotski (1999, p.76): “A internalização das atividades socialmente enraizadas e historicamente desenvolvidas constitui o aspecto característico da psicologia humana; é a base do salto qualitativo da psicologia animal para a psicologia humana".

Falar de sujeito em Vigotski é tratar de um ser em constante metamorfose. Apoiado na carga genética inerente a cada um, o ser se torna único em contato com o outro. É na coletividade, no acesso aos costumes, informações, valores e objetos presentes e disponibilizados por cada sociedade que o ser humano vai construindo sua concepção de mundo e de si próprio, se (re)criando enquanto sujeito humano.

Superada a dicotomia entre o ser biológico e social, deveríamos, por agora, encerrar essa discussão, porém é justamente esse aspecto que gera os maiores ganhos no desenvolvimento de uma concepção mais ampla do sujeito.

\section{Segundo Smolka (apud VIGOTSKI, 2010, p. 40):}

Com base na concepção de que o homem cria suas próprias condições de existência, podemos pensar não só na satisfação das necessidades pela produção de instrumentos (artefatos e signos), mas na criação de novas condições de possibilidades que se abrem constantemente, num movimento, contraditório e infindável, de transformação.

É justamente na dialética da relação do ser com o outro e consequente tentativa de compreensão do outro, do mundo e de si mesmo, que se abrem para o sujeito as portas à sua constituição e (re)construção do mundo, conforme podemos encontrar em Imaginação e criação na infância (VIGOTSKI, 2010, p. 40):

Se a vida ao seu redor não o coloca diante de desafios, se as suas reações comuns e hereditárias estão em equilíbrio com o mundo circundante, então não haverá base alguma para a emergência da criação. O ser completamente adaptado ao mundo nada desejaria, não teria nenhum anseio e, é claro, nada poderia criar. Por isso, na base da criação há sempre uma inadaptação da qual surgem necessidades, anseios e desejos.

Desse modo, não apenas o contato com o social recria o homem, mas este detém a capacidade inigualável de reconstruir o social. Essa função torna-se ainda mais emergente nas atuais sociedades, influenciadas pela agilidade e rapidez favorecidas pelo uso da tecnologia. Ser homem hoje, mais do que formar-se criticamente com e por uma sociedade e tempos próprios, é ser capaz de interferir naquilo que se encontra preestabelecido, desenvolvendo-o e desenvolvendo a si próprio. Desse modo, pode-se resgatar o termo "identidades fluidas" defendidas por Pierre Levy (1999), mas não no sentido de "perda" de identidade, mas na necessidade constante de sua recriação. Se dizemos que o homem se recria no social, admitimos uma subjetividade sempre em construção, 
inovadora, criativa, não previsível. É dessa subjetividade de que trata Vigotski. É esse caminho teórico que queremos aqui tomar ao tratar da formação coletiva do ser humano/da constituição social do sujeito, importantes aos nossos pesquisados: sujeitos estes, históricos, datados, únicos e que constroem e são construídos pelo outro e pela linguagem no social.

Para finalizar nossa concepção de sujeito a partir de Vigotski, recuperamos, simultaneamente aos aspectos acima enumerados, o sujeito estético. Se este não é um lado enfatizado ou mesmo considerado do ser humano, para nós, nos últimos anos, passou a ser cada vez mais essencial. No livro Psicologia pedagógica, Vigotski (2003, p. 239) nos alerta que:

Aqui está a chave para a tarefa mais importante da educação estética: inserir as reações estéticas na própria vida. A arte transforma a realidade não só em construções da fantasia, mas também na elaboração real das coisas, dos objetos e das situações. [...] a poesia também não está apenas onde existem grandes criações artísticas, mas em todos os lugares onde a palavra humana estiver.

Vigotski nos revela um sujeito que, a partir do social, ressurge enquanto ser único, individual, criativo. Como diz Pino (2005), o autor russo transforma nossa concepção de linguagem e da formação-desenvolvimento do homem e nos oferece uma visão de homem em constante constituição, incompleto, e comprometido com a sociedade e tempos próprios.

\section{O sujeito em Bakhtin}

Discutir a noção de sujeito em Bakhtin implica uma leitura abrangente de seus textos e exige um percurso atento sobre os escritos de seu Círculo. Isso porque não podemos afirmar que há, nessas obras, uma teoria do sujeito ou sobre o sujeito que possa se emoldurar, como bem diz Faraco (2001, p. 9) numa "chave classificatória simples". O que podemos extrair nesse itinerário - que pode ser tão diverso assim como o são os estudos sobre Bakhtin - são indicações sobre como este autor e seu Círculo pensam o sujeito e o deixam entrever em suas formulações sobre a linguagem, a ética e a estética.

Para focalizar esse sujeito, é necessário compreendermos que a construção teórica do Círculo de Bakhtin se firma nas bases do materialismo histórico-dialético tendo a dialética como método de trabalho. No entanto, por conceber a realidade como essencialmente contraditória e em permanente transformação, sua dialética é oposta à dialética de Hegel, que, ao se organizar em uma sistemática mecânica de oposições, priva o diálogo de sua condição essencial. A dialética bakhtiniana nasce do diálogo e nele se prolonga, colocando pessoas e textos em um permanente processo dialógico (FREITAS, 1997).

Partindo dessa dialética dialógica, encontramos construída no Círculo de Bakhtin uma visão totalizante, não fragmentada da realidade, que enraizada na história compreende o homem como um conjunto de relações sociais, como um sujeito social da e na história. Mas esse social não abafa o individual. O sujeito bakhtiniano é constituído nas relações com outros sujeitos. Para ser sujeito, é neces- sário haver um outro que o constitua. O eu só se torna um eu quando o outro se volta para o eu na condição de um tu. Emerson (2003, p. 274) compreende que Bakhtin se opõe, nesse sentido, ao dizer de Buber: "Ao me tornar um Eu, eu digo Tu", pois o autor russo assume a posição de que é totalmente impossível a existência de um "eu" sem um "outro". Assim, Bakhtin não confere ao eu um lugar central, mas coloca o outro como eixo de todo seu trabalho. Essa mudança de ponto de referência é considerada por Ponzio (2008) como a revolução bakhtiniana em relação à proposta da filosofia ocidental e da visão de mundo dominante em nossa cultura. Como diz Freitas (2013), Bakhtin em seus textos vai muito além da relação eu-tu proposta pela fenomenologia. Não se restringe ao movimento de um eu que se orienta para o outro, mas concebe o outro como condição necessária para a constituição do eu.

O homem não pode, portanto, ser pensado fora de suas relações sociais, uma vez que é nas relações com outros sujeitos que se constitui enquanto tal.

Em O Freudismo, Bakhtin [Volochínov] (2007) questiona a concepção de indivíduo biológico abstrato, assegurando que, para entrar na história, ao homem é necessário outro nascimento, o social: "O homem não nasce como um organismo biológico abstrato, mas como fazendeiro ou camponês, burguês ou proletário: isso é o principal. Ele nasce como russo ou francês e, por último, nasce em 1800 ou 1900" (BAKHTIN [VOLOCHÍNOV], 2007, p. 11). Portanto, a consciência possui uma orientação social, o que distancia o Círculo de Bakhtin da concepção moderna de sujeito pensante.

As questões do psiquismo humano são mais detidamente discutidas em Marxismo e Filosofia da Linguagem (BAKHTIN [VOLOCHÍNOV], 1988), publicado na Rússia em 1929. Como produto social, o psiquismo humano localiza-se fora do sujeito, ou melhor, situa-se entre duas esferas da realidade: o organismo e o mundo exterior numa região de fronteira entre o externo e o interno, entre o eu e o outro. A ligação entre esses dois mundos se dá pelo signo que é, por excelência, ideológico. Esse encontro entre o organismo e o mundo exterior, não é físico: "o organismo e o mundo se encontram no signo" (BAKHTIN [VOLOCHÍNOV], 1988, p.49). A atividade psíquica constitui a expressão semiótica do contato entre o organismo e o meio exterior. Eis porque "o psiquismo interior não deve ser analisado como uma coisa; ele não pode ser compreendido e analisado senão como um signo" (BAKHTIN [VOLOCHÍNOV], 1988, p. 49).

A consciência, na perspectiva do Círculo de Bakhtin, só adquire sua materialidade no encontro/confronto com outra consciência, já que os signos emergem das interações que se concretizam no interior de um grupo social determinado. Dessa forma, o sujeito para Bakhtin e seu Círculo é pensado, como diz Sobral (2009), em termos de uma interação constitutiva com a sociedade: ele precisa da sociedade para existir e a constitui em suas relações com outros sujeitos. "Somos povoados pelo outro e nossas relações com o outro faz de nós e deles os elementos constituintes da sociedade" (SOBRAL, 2009, p. 48). 
Porém, afirmar que a consciência do sujeito só se constitui no processo de interação social e a partir do processo de representação ideológica do mundo não significa concordar que o homem não é dotado de uma constituição psíquica particular que constitui sua própria identidade. Identidade que só pode ser concebida na dimensão da intersubjetividade, no reconhecimento de que só existe um "eu" na medida em que este é por um "outro" reconhecido e assimilado.

Em “Arte e Responsabilidade" (BAKHTIN, 2003a), encontramos o pressuposto de que o homem só pode ser compreendido em sua unicidade. Mas, também aqui, essa "unidade" não nos remete à noção de um sujeito uno, racional, individualizado. $\mathrm{O}$ agir humano é sempre situado e inclui o outro em sua concretude, porém, além de ganhar sua unidade dentro do contexto da cultura, só pode ser compreendido como um ato particular do pensamento real como evento.

É no texto Para uma filosofia do ato (BAKHTIN, 1993), ${ }^{1}$ escrito entre 1919-1921, que encontramos as primeiras formulações sobre o sujeito em Bakhtin. Podemos entrever nesse livro, permeado por questões éticas, algumas ideias importantes para a compreensão da concepção bakthiniana de sujeito.

Nele Bakhtin discute duas situações: de que maneira o eu se constitui como uma entidade que executa atos responsáveis no mundo; como o eu e os atos por ele praticados se relacionam com a cultura. Compreende, dessa forma, que um ser humano que pensa participativamente não separa a realização de seu ato, de seu produto (FREITAS, 2013, p. 186).

Para o autor, "- a ciência, a arte e vida - só adquirem unidade no indivíduo que os incorpora à sua própria unidade. [...] Arte e vida não são a mesma coisa, mas devem tornar-se algo singular em mim, na unidade da minha responsabilidade" (BAKHTIN, 2003a, p. XXXIII-XXXIV).

Esse caráter da responsabilidade ou responsividade do sujeito designada pela palavra russa otveststevennost também é destacado em Para uma filosofia do ato (BAKHTIN, 1993). Todo homem é responsável pelos seus atos e responsivo aos outros sujeitos neles envolvidos. A responsabilidade não pode, portanto, ser entendida como um valor absoluto, já que há uma interdependência constitutiva entre o processo e o conteúdo do ato em si que inclui outro sujeito igualmente responsável, ambos inseridos na história e numa dada sociedade. Desses apontamentos, depreende-se que o sujeito está sempre em constituição, num movimento contínuo entre o eu e o outro.

Bakhtin (1993) entende o ato como algo que o eu deve encarar e compreender de forma racional, consciente e responsável. A realidade da unicidade unitária do mundo real é garantida pelo reconhecimento da participação única do eu neste mundo, pelo meu "não álibi" nele.

O dever arquitetônico de realizar o lugar único no ser evento único é determinado antes, e acima de tudo, como uma contraposição entre o eu e o outro. Em Para

\footnotetext{
Mantivemos a data de 1993 que está na edição em inglês publicada nesse ano a qual foi traduzida por Faraco, A. A. e Tezza, C. s/d apenas para uso didático e acadêmico.
}

uma filosofia do ato, Bakhtin (1993) apresenta, portanto, um sujeito não sistêmico e, sobretudo interpessoal, responsável, no qual o outro é constitutivo do eu, sem o qual eu não posso ser.

Em $O$ autor e a personagem da atividade estética (2003b), um texto produzido por Bakhtin entre 19201923, há uma preocupação com os modos pelos quais chegamos a criar imagens dos outros e imagens de nós mesmos para os outros. A criação dessas imagens é a essência da atividade estética. No interior dessa discussão apresenta uma concepção do eu a partir de três categorias inter-relacionadas nas quais há diferentes movimentos entre o eu e o outro: o "eu-para-mim", "eu-para-o-outro" e "o-outro-para-mim".

Essa tríade sintetiza uma perspectiva que pode ser aplicada para a compreensão da produção da subjetividade: um eu que se constitui a partir do outro mas na interação e não na fusão com o outro. Mais uma vez é enfatizado por Bakhtin o papel essencial da alteridade na modelagem e constituição do sujeito. (FREITAS, 2013, p. 191).

Bakhtin (2003b) nos permite pensar o sujeito como um ser inacabado cuja existência depende do olhar que dele tem o outro. O que não é acessível ao campo de visão de uma pessoa sobre si mesma pode ser visto por um outro que, do lugar onde se situa, por sua distância, lhe permite um excedente de visão que o completa em uma completude sempre incompleta. Os conceitos de excedente de visão, de exotopia e de acabamento da personagem, próprios da estética, permitem-nos pensar na noção de sujeito também no mundo ético. O princípio de acabamento do todo de uma obra é dado por aquilo que o autor vê e sabe da vida do personagem. Já na vida não temos um autor e é pela visão do outro que posso ter experiência de mim mesmo, ou seja, minha existência, única e irrepetível é criada pelo acabamento que o outro me dá. Nessa perspectiva, Freitas (2013) comenta que o homem tem uma necessidade estética absoluta do outro e na vida de um homem singular a relação eu-outro é irreversível e dada de uma vez por todas. Sem o outro, o eu não pode se constituir.

Bakhtin, como um filósofo da linguagem, não poderia deixar de colocar também sua discussão do eu e do outro numa perspectiva discursiva. É no livro de Bakhtin sobre Dostoiévski e em suas reflexões sobre o romance nos anos 1930 que a discussão do eu como um aspecto discursivo emerge apresentando a linguagem como forma de moldar o eu ao convertê-lo em discurso interior. Para Morson e Emerson (2008), Bakhtin imagina o eu como uma conversação, que se apresenta às vezes como uma arena de vozes discordantes que falam de diferentes posições e estão investidas de diferentes graus de autoridade. $\mathrm{Na}$ perspectiva dialógica de Bakhtin, tanto o eu quanto a palavra são abordados dialogicamente. Para o autor, é impossível compreender o eu fora do diálogo.

Nos “Apontamentos de 1970-1971”, Bakhtin (2003c) diz que, além de suas próprias palavras, o sujeito vive imerso nas palavras do outro e, na busca de compreendê-las, envolve-se em uma tensa luta dialógica entre as pala- 
vras próprias e as alheias, buscando tornar próprio o que de início foi construído com o outro: das palavras alheias às próprias palavras. $\mathrm{O}$ objetivo dessa assimilação da palavra do outro adquire um sentido importante no processo de formação ideológica do homem, portanto também no processo constitutivo do eu (FREITAS, 2012).

Enfim, apreendemos em nosso diálogo com Bakhtin e seu Círculo uma concepção de sujeito não abstrato, mas integrado à vida, sujeito social da e na história, constituinte de uma sociedade e por ela constituído, sujeito que se constitui na alteridade, sujeito como ser de linguagem, sujeito ativo e dialógico que executa no mundo atos responsáveis e é responsivo aos outros sujeitos.

\section{A compreensão de sujeito nas pesquisas do LIC/UFJF}

É nessa visão de homem, articulada aos construtos teóricos de Vigotski e de Bakhtin e seu Círculo, que se insere a compreensão de sujeito do grupo LIC/UFJF. Muitos foram os sujeitos de pesquisa do grupo, desde sua primeira investigação: professoras em exercício e aposentadas com suas histórias de vida e formação; crianças e adolescentes e suas práticas de leitura e escrita; adolescentes imersos na tecnologia e na construção da escrita na internet e na escola; professores, alunos do ensino fundamental e médio, na descoberta da aprendizagem na era da internet; professores e alunos do Colégio de Aplicação João XXIII, professores e alunos do curso de Pedagogia da Universidade Federal de Juiz de Fora percebendo computador/ internet como instrumentos culturais de aprendizagem.

Sempre coerentes com o referencial teórico que nos ancora e no diálogo constante com outros pesquisadores que compartilham conosco seus estudos da perspectiva histórico-cultural, nas pesquisas empreendidas pelo grupo até hoje houve uma grande preocupação em perceber o processo de pesquisa como uma relação dialógica. Nessa relação, o pesquisador é também um sujeito que experiencia com o outro o "acontecer" da pesquisa. Pesquisador e pesquisado são sujeitos que interagem em um ato dialógico e responsivo que pressupõe que todos têm voz e assumem uma atitude responsiva ativa. Mas nesse diálogo, nenhuma voz se sobrepõe.

Como, nesse diálogo, produzir o distanciamento necessário para que possa efetivamente analisar os resultados dessa interação sujeito-pesquisador/sujeito-pesquisado? No caso das pesquisas do LIC/UFJF, esses elementos muitas vezes se "misturaram", pois os pesquisadores e seus sujeitos de pesquisa pertenciam a um mesmo campo de trabalho, no caso a Educação, professores pesquisando professores ou escolas, um universo tão familiar. A esse respeito, Amorim (2004, p. 30-31, grifo nosso) afirma que

Podemos também pensar naquela situação em que o pesquisador não se diferencia em nada de seu sujeito de pesquisa (por pertencer à mesma classe social, ou à mesma geração, etc.), mas, de todo modo, a diferença que permeia o ato de pesquisa estará lá, tornando esse sujeito um outro. Colocar esse sujeito no lugar de objeto de estudo instaura entre o sujeito cognoscente e o sujeito a conhecer uma relação de alteridade fundamental que emerge de uma diferença de lugar na construção do saber. O outro se torna estrangeiro pelo simples fato de eu pretender estudá-lo.

É nesse momento que recorremos ao conceito de exotopia de Bakhtin: afastamo-nos do campo e dos sujeitos para que possamos, então, numa posição extracampo, olharmos para o processo empreendido durante a pesquisa e analisá-lo.

É pois, a partir de um lugar exotópico, $[\ldots]$ que a busca do encontro se dá. Os métodos, as técnicas e os projetos podem tratar de modo mais ou menos explícito a questão da alteridade, mas eles contêm sempre estratégias de encontro. Como encontrar o outro, como fazê-lo falar, como se fazer ouvir, como compreendê-lo, como traduzilo, como influenciá-lo e se deixar influenciar por ele [...] (AMORIM, 2004, p. 31).

Alguns pesquisadores do grupo narram em seus trabalhos que esse não é um processo tranquilo, o que é altamente compreensível, se entendermos que a pesquisa acontece por meio do diálogo; é justamente por meio dele que "o pesquisador se torna capaz de construir/desconstruir/reconstruir conhecimentos acerca do outro" (FREITAS; RAMOS, 2010, p. 9). Essa construção/desconstrução/reconstrução implica ainda que, durante a pesquisa, mudanças podem ocorrer tanto no pesquisado quanto no pesquisador, o que nos remete a um outro aspecto que caracteriza a concepção de sujeito nas pesquisas do grupo.

Ao pensarmos uma pesquisa, estamos sempre buscando uma compreensão ativa na relação com os sujeitos geradora de mudanças pessoais e contextuais, mas sem prevermos explicitamente uma intervenção planejada. Em nossos projetos de pesquisa intencionamos, portanto, além de compreender a realidade na qual nos inserimos, levar seus participantes a uma reflexão crítica de sua prática, constituindo-se, portanto, a pesquisa como um espaço de formação (FREITAS; RAMOS; SANTOS, 2009).

Em nossas pesquisas, pudemos notar significativas mudanças: não só no pensamento e nas atitudes de nossos sujeitos-participantes como também no interior dos estabelecimentos que nos serviram de campo. De fato, concluímos que fazer pesquisa na abordagem histórico-cultural "consiste não só em descrever a realidade, mas também explicá-la, buscando, nesse movimento, transformá-la" (FREITAS, 2010, p. 23).

Ao final dessa reflexão cabe dizer que a concepção de sujeito que ancora as pesquisas do grupo LIC/UFJF parte sim das concepções presentes nos trabalhos de Vigotski e de Bakhtin e seu Círculo, mas não se trata de um conceito duro e impenetrável. Coerente com o pensamento dos teóricos russos e com os fundamentos da perspectiva histórico-cultural, podemos afirmar que nosso sujeito é um sujeito participante, responsivo, ativo, aprendente-ensinante, dialógico.

\section{Considerações finais}

$\mathrm{Na}$ constituição do sujeito na perspectiva histórico-cultural, percebemos o movimento dialético do individual e do social: sem os outros não há um eu e sem eu 
não há um outro. São muitas e diferentes as relações que o sujeito estabelece com outros sujeitos, mas nelas ele se altera, se constitui, sem deixar de ser ele mesmo. Nesse processo que é experimentado participativamente se forma o sujeito responsável, único, sempre em formação. Um sujeito responsivo que em suas relações sociais e históricas com os outros sujeitos é um elemento constitutivo da sociedade sem a qual ele próprio não existe.

Pensar o homem nessa perspectiva implica pensar a educação numa perspectiva polissêmica, compreendendo que o ato de ensinar/aprender se faz por meio da diferenciação, pois o lugar de onde o sujeito fala, olha, sente, age é sempre partilhado. Nesse sentido, o aluno não é um mero objeto do ensino, mas um sujeito que exige o reconhecimento do outro - o professor, o colega de classe - para conferir significado ao que diz, faz, sente, pensa na e pela escola. O professor, por sua vez, passa também a ser compreendido como um sujeito sempre em formação, não mais o sujeito controlador de aprendizagem do aluno e reprodutor da ciência e da cultura, mas cuja identidade se forja também em território instável, em permanente construção. E, formando uma tríade, o conhecimento - organização sistemática dos saberes produzidos nas práticas sociais - vem agregar à relação professor-aluno um grande desafio: o da autoria. "Refletindo sobre o seu vivido, escrevendo seus próprios textos e estabelecendo novas relações com o já produzido" (GERALDI, 2010, p. 100), professores e alunos, sujeitos do processo ensino/aprendizagem, terão de aprender, juntos, a "percorrer caminhos inexistentes porque eles se fazem no percurso" (GERALDI, 2010, p. 100).

Enfim, mais importante do que formatar uma concepção de sujeito e educação no Círculo de Bakhtin e em Vigotski, é pensar nas condições de possibilidades que suas teorias nos oferecem para compreendermos o mundo em que vivemos e a nós mesmos.

\section{Referências}

AMORIM, M. O pesquisador e seu outro: Bakhtin nas ciências humanas. São Paulo: Musa, 2004.

BAKHTIN, M. Toward a Philosophy of the act. Tradução de Vadim Liapunov. Texas: University of Texas Press, 1993.

BAKHTIN, M. Arte e responsabilidade. In: Estética da criação verbal. São Paulo: Martins Fontes, 2003a. p. XXXIIIXXXIV

BAKHTIN, M. O autor e a personagem. In: Estética da criação verbal. São Paulo: Martins Fontes, 2003b. p. 3-194.

BAKHTIN, M. Os apontamentos de 1970-1971. In: Estética da criação verbal. São Paulo: Martins Fontes, 2003c. p. 367-392.

BAKHTIN, M. [VOLOCHÍNOV, V. N.]. Marxismo e Filosofia da linguagem. São Paulo: Hucitec, 1988.

BAKHTIN, M. [VOLOCHÍNOV, V. N.]. O Freudismo. São Paulo: Perspectiva, 2007.

EMERSON, C. Os 100 primeiros anos de Mikhail Bakhtin. São Paulo: DIFEL, 2003.
FARACO, C. A. Apresentação. In: FARACO, C. A. et al. (Org.). Diálogos com Bakhtin. Curitiba: UFPR, 2001. p. 9-20.

FREITAS, M. T. A. Nos textos de Bakhtin e Vigotski: um encontro possível. In: BRAIT, B. (Org.). Bakhtin, dialogismo e construção de sentido. Campinas: UNICAMP, 1997. p. 311-330.

FREITAS, M. T. A. Discutindo sentidos da palavra intervenção na pesquisa de abordagem histórico-cultural. In: FREITAS, M. T. A.; RAMOS, B. S. (Org.). Fazer pesquisa na abordagem histórico-cultural: metodologias em construção. Juiz de Fora: UFJF, 2010. p. 13-24.

FREITAS, M. T. A. A linguagem como constituidora da consciência e elemento transformador no processo da vida humana: uma leitura histórico-cultural. In: REUNIÃO ANUAL DA ANPEd, 35., 2012, Porto de Galinhas - PE. Educação, cultura, pesquisa e projetos de desenvolvimento: o Brasil do século XXI. Rio de Janeiro: ANPEd, 2012. v.1. Disponível em: <http://35reuniao.anped.org.br/images/stories/trabalhos/ GT20\%20Trabalhos/GT20-2186 int.pdf>. Acesso em: 02 abr. 2013.

FREITAS, M. T. A. Identidade e alteridade em Bakhtin. In: PAULA, L. de; STAFFUZA, G. (Org.). Círculo de Bakhtin: pensamento interacional. Campinas: Mercado de Letras, 2013. v. 3, p.183-199.

FREITAS, M. T. A.; RAMOS, B. S.; SANTOS, I. S. A trajetória de pesquisa do grupo LIC: formação de professores, letramento e tecnologias digitais. In: MIRANDA, S. R.; MARQUES, L. P. (Org.). Trajetórias: caminhos na pesquisa em Educação. Juiz de Fora: UFJF, 2009. p. 19-43.

FREITAS, M. T. A.; RAMOS, B. S. (Org.). No fluxo dos enunciados, um convite à contrapalavra. In: _. Fazer pesquisa na abordagem histórico-cultural: metodologias em construção. Juiz de Fora: UFJF, 2010. p. 7-12.

GERALDI, J. W. A aula como acontecimento. São Carlos: Pedro \& João, 2010.

LEVY, P. Cibercultura. São Paulo: Ed. 34, 1999.

MORSON, G. S.; EMERSON, C. Mikhail Bakhtin: criação de uma prosaística. São Paulo: EDUSP, 2008.

PINO, A. As marcas do humano: às origens da constituição cultural da criança na perspectiva de Lev S. Vigotski. São Paulo: Cortez, 2005.

PONZIO, A. A revolução Bakhtiniana. São Paulo: Contexto, 2008.

SOBRAL. A. Concepção de Sujeito do Círculo, In: Do dialogismo ao gênero: as bases do pensamento do círculo de Bakhtin. Campinas: Mercado de Letras, 2009. p.47-60.

VIGOTSKI, L. S. A Formação Social da Mente. São Paulo: Martins Fontes, 1999.

VIGOTSKI, L. S. A construção do pensamento e da linguagem. São Paulo: Martins Fontes, 2001.

VIGOTSKI, L. S. Psicologia Pedagógica. Porto Alegre: Artmed, 2003.

VIGOTSKI, L. S. Imaginação e criação na infância. São Paulo: Ática, 2010.

Recebido em: 29 de agosto de 2013 Aceito em: 30 de outubro de 2014 